\title{
New Agriculture Technology in Modern Farming
}

\author{
M. Manida ${ }^{* 1}$, M. K. Ganeshan ${ }^{2}$ \\ ${ }^{I}$ Ph.D Research Scholar, Department of Commerce, Alagappa University, Karaikudi, India \\ E-mail: manidamcom@gmail.com \\ ${ }^{2}$ Ph. D. Research Scholar, Alagappa Institute of Management, Alagappa University, Karaikudi, India
}

\begin{abstract}
Progressions in the field of science and innovation alongside worldwide urbanization are the main considerations driving the course and advancement of horticultural examination. Ascend in per capita pay in non-industrial countries, word-related changes, and worldwide linkages have changed the food inclinations. These patterns together with the augmentation in the general population represent an assessment to horticulture for creating more and healthier food. An increase in the efficiency of horticulture by utilizing strategies of traditional agribusiness is representing a limit. The threat to the environment posed by reliance on synthetic manures and pesticides for increasing efficiency and irritation across the board is a major factor impacting global food production. These trends suggest that new farming innovations are urgently needed and that these innovations should be integrated into traditional agribusiness. Vertical cultivating and natural cultivating are the exploration territories to battle these requirements. Vertical cultivating utilizes vertical stacking of the ranches and little land can be used for more creation. This strategy is appropriate for the quickly developing worldwide metropolitan population can be met food supply from inside the urban communities and along these lines decreasing the transportation cost and climate weakening brought about by energizes all the while. Natural cultivating again depends on of minimization of the synthetic contributions to the horticulture and henceforth is climate cordial. As a result, these processes can be employed to increase production and profitability in order to meet the growing food demand.
\end{abstract}

Keywords — Organic Farming; Climate Change; Sustainability; Agribusiness; Economy.

\section{Introduction}

Advancement is more significant in current farming than any other time in recent memory. The business in general is confronting enormous difficulties, from increasing expenses of provisions, a lack of work, and changes in purchaser inclinations for straightforwardness and supportability. There is expanding acknowledgment from agribusiness enterprises that arrangements are required for these difficulties. Over the most recent 10 years, farming innovation has seen a tremendous development in speculation, with $\$ 6.7$ billion put resources into the most recent 5 years and $\$ 1.9$ billion in the most recent year alone. Significant innovation advancements in the space have centered around zones like indoor vertical cultivating, mechanization and mechanical technology, domesticated animals innovation, present day nursery rehearses, exactness farming and man-made consciousness, and square chain. The report communicates that, notwithstanding the way that solicitation is determinedly creating, by 2050 we ought to make $70 \%$ more food.

Meanwhile, a great deal of overall GDP has contracted to just 3 percent, $33 \%$ its responsibility just numerous years earlier. Around 800 million people generally speaking experience the evil impacts of craving. In addition, under an old news circumstance, 8 percent of the absolute people (or 650 million) will regardless be undernourished by 2030 . Entirely no improvement has happened occupied with late in any case, nothing to show that food deficiency and needing will not be an issue in the coming numerous years.

To address these troubles will require a purposeful effort by governments, monetary patrons, and creative agrarian advances. Agriculture 4.0 will by and by don't depend after applying water, composts, and pesticides reliably across entire fields. Taking everything into account, farmers will use the base sums required and target very certain domains. The report further communicates that, farms and agrarian undertakings ought to be run in a surprising manner, basically due to movements in advancement like sensors, devices, machines, and information development. Future agribusiness will use current developments like robots, temperature and clamminess sensors, aeronautical pictures, and GPS advancement. These general contraptions and precision agriculture and mechanical structures will allow farms to be more helpful, gainful, safe, and innocuous to the environment.

Table 1. Smart Farming

\begin{tabular}{|l|l|}
\hline 1. & Sensing Technologies \\
\hline 2. & Software Applications \\
\hline 3. & Communications Systems( Cellular) \\
\hline 4. & Telematics Positioning Technologies \\
\hline 5. & Hardware and software Systems \\
\hline 6. & Data Analytics Solutions \\
\hline
\end{tabular}




\section{Objectives of the Study}

- To study on recent trends in agriculture technology.

- To examine the recent trends in performance of agricultural growth technology

\section{Recent Trends in Agricultural Growth Technology}

\subsection{Indoor Vertical Farming}

Indoor vertical cultivating can expand crop yields, defeat restricted land territory, and even lessen cultivating effect on the climate by chopping down distance went in the production network. Indoor vertical cultivating can be characterized as the act of developing, that produce stacked one over another in a shut and controlled climate. By utilizing developing racks mounted vertically, it essentially diminishes the measure of land space expected to develop plants contrasted with customary cultivating strategies. This kind of developing is regularly connected with city and metropolitan cultivating in view of its capacity to flourish in restricted space. Vertical ranches are one of a kind in that a few arrangements don't need soil for plants to develop. Most are either aquaculture, where vegetables are filled in a supplement thick bowl of water, or aerologic, where the plant roots are deliberately showered with water and supplements. In lieu of normal daylight, fake develop lights are utilized. From maintainable metropolitan development to boosting crop yield with diminished work costs, the benefits of indoor vertical cultivating are clear.

Vertical cultivating can handle factors like light, stickiness, and water to accurately gauge all year, expanding food creation with solid harvests. The decreased water and energy utilization improves energy preservation vertical homesteads utilize around $70 \%$ less water than conventional ranches. Work is moreover essentially lessened by using robots to manage harvesting, planting, and coordination's, handling the test farms face from the current work insufficiency in the agriculture business. Vertical cultivating has been a sci-fi subject as far back as the 1950s and maybe further and now it's experimentally feasible as well as will be monetarily practical inside the decade. Vertical ranch innovation vertical cultivating a segment of metropolitan horticulture is the act of creating food in vertically stacked layers. This offers numerous favourable circumstances. Maybe the most evident is the capacity to develop inside metropolitan conditions and in this manner have fresher nourishments accessible quicker and at lower costs. Nonetheless, vertical cultivating will not be restricted to simply metropolitan conditions like at first anticipated. Ranchers on the whole zones can utilize it to utilize accessible land and to develop crops that wouldn't regularly be suitable in those areas.

\subsection{Farm Automation}

Ranch mechanization, frequently connected with "shrewd cultivating", is innovation that makes cultivates more proficient and computerizes the harvest or animals creation cycle. An expanding number of organizations are dealing with mechanical technology advancement to create drones, self-ruling farm haulers, automated collectors, programmed watering, and cultivating robots. Albeit these advances are genuinely new, the business has seen an expanding number of customary horticulture organizations receive ranch robotization into their cycles.

New headways in advancements going from mechanical technology and robots to $\mathrm{PC}$ vision programming have totally changed present day agribusiness. The essential objective of ranch robotization innovation is to cover simpler, commonplace assignments. Some significant innovations that are most generally being used by ranches include: gather mechanization, independent farm haulers, cultivating and weeding, and drones. Ranch mechanization innovation tends to significant issues like a rising worldwide populace, ranch work deficiencies, and changing customer inclinations. The advantages of mechanizing customary cultivating measures are fantastic by handling issues from shopper inclinations, work deficiencies, and the ecological impression of cultivating.

\subsection{Livestock Farming Technology}

The customary animals industry is an area that is broadly ignored and under-overhauled, despite the fact that it is seemingly the most fundamental. Domesticated animals give truly necessary inexhaustible, common assets that we depend on consistently. Animals the executives has generally been known as maintaining the matter of poultry ranches, dairy ranches, cows farms, or other animals related agribusinesses. Domesticated animal's supervisors should keep precise monetary records, direct specialists, and guarantee appropriate consideration and taking care of creatures. Notwithstanding, late patterns have demonstrated that innovation is reforming the universe of domesticated animals the executives. New advancements in the previous 8-10 years have made immense upgrades to the business that makes following and overseeing animals a lot simpler and information driven. This innovation can come as wholesome advances, hereditary qualities, computerized innovation, and the sky is the limit from there.

Animal's innovation can upgrade or improve the profitability limit, government assistance, or the executives of creatures and domesticated animals. Animals' innovation can upgrade or improve the efficiency limit, government assistance, or the board of creatures and animals. The idea of the 'associated cow' is a consequence 
of increasingly more dairy groups being fitted with sensors to screen wellbeing and increment profitability. Putting singular wearable sensors on dairy cattle can monitor every day movement and wellbeing related issues while giving information driven bits of knowledge to the whole crowd. This information created is additionally being transformed into significant, noteworthy bits of knowledge where makers can look rapidly and effectively to settle on snappy administration choices.

Creature genomics can be characterized as the investigation of taking a gander at the whole quality scene of a living creature and how they collaborate with one another to impact the creature's development and advancement. Genomics help animals makers comprehend the hereditary danger of their crowds and decide the future benefit of their animals. By being vital with creature determination and reproducing choices, dairy cattle genomics permits makers to upgrade productivity and yields of animals' crowds. Sensor and information advances have colossal advantages for the current animals industry. It can improve the efficiency and government assistance of domesticated animals by distinguishing wiped out creatures and astutely perceiving opportunity to get better. PC vision permits us to have a wide range of fair information that will get summed up into significant, noteworthy experiences. Information driven dynamic prompts better, more proficient and opportune choices that will propel the profitability of domesticated animals crowds.

\subsection{Modern Greenhouses}

In late many years, the Greenhouse business has been changing from limited scope offices utilized principally for exploration and tasteful purposes (i.e., botanic nurseries) to altogether more enormous scope offices that contend straightforwardly with land-based traditional food creation. Consolidated, the whole worldwide nursery market as of now delivers almost US $\$ 350$ billion in vegetables yearly, of which U.S. creation includes short of what one percent.

These days, in enormous part because of the gigantic ongoing upgrades in developing innovation, the business is seeing a blooming like no time previously. Nurseries today are progressively arising that are enormous scope, capitalimplanted, and metropolitan focused.

The whole worldwide nursery market presently creates almost US $\$ 350$ billion in vegetables every year. As the market has developed drastically, it has additionally experienced clear patterns as of late. Present day nurseries are turning out to be progressively tech-substantial, utilizing LED lights and computerized control frameworks to consummately tailor the developing climate. Effective nursery organizations are scaling altogether and found their developing offices close to metropolitan centre points to profit by the consistently expanding interest for neighbourhood food, regardless of the period. To achieve these accomplishments, the nursery business is additionally getting progressively capital-imbued, utilizing adventure subsidizing and different sources to work out the foundation important to contend in the current market.

\subsection{Precision Agriculture}

Agribusiness is going through advancement innovation is turning into a fundamental piece of each business ranch. New exactness horticulture organizations are creating advancements that permit ranchers to augment yields by controlling each factor of harvest cultivating, for example, dampness levels, bother pressure, soil conditions, and miniature environments. By giving more exact procedures to planting and developing harvests, exactness agribusiness empowers ranchers to build proficiency and oversee costs. Accuracy agribusiness organizations have discovered a gigantic chance to develop. The agribusiness market is expected to reach $\$ 43.4$ billion by 2025 (Grand View Research Incorporation). The arising new age of ranchers is pulled in to quicker, more adaptable new businesses that methodically amplify crop yields.

\subsection{Blockchain}

Blockchain's capacity of following possession records and alter opposition can be utilized to tackle dire issues like food misrepresentation, wellbeing reviews, inventory network shortcoming and food detestability in the current food framework. Blockchain's remarkable decentralized construction guarantees confirmed items and practices to make a business opportunity for premium items with straightforwardness. Food discernibility has been at the focal point of ongoing sanitation conversations, especially with new headways in blockchain applications. Because of the idea of short-lived food, the food business at entire is incredibly powerless against committing errors that would eventually influence human lives. When food borne sicknesses undermine general wellbeing, the initial step to main driver investigation is to find the wellspring of pollution and there is no capacity to bear vulnerability. Blockchain can be utilized to settle critical issues like food extortion, wellbeing reviews, store network failure and food discernibility in the current food framework. Thusly, recognisability is basic for the food production network. The current correspondence structure inside the food biological system makes recognisability a tedious errand since some elaborate gatherings are as yet following data on paper. The design of blockchain guarantees that every player along the food esteem chain would produce and safely share information focuses to make a responsible and recognizable framework. Huge information focuses with 
marks that explain possession can be recorded immediately with no change. Thus, the record of a food thing's excursion, from homestead to table, is accessible to screen progressively.

The utilization instances of blockchain in food go past guaranteeing food handling. It likewise enhances the current market by building up a record in the organization and adjusting market estimating. The customary value system for purchasing and selling depends on decisions of the elaborate players, instead of the data given by the whole worth chain. Offering admittance to information would make an all encompassing image of the market interest. The blockchain application for exchanges may upset customary item exchanging and supporting too. Blockchain empowers checked exchanges to be safely imparted to each major part in the food store network, making a commercial centre with monstrous straightforwardness.

\subsection{Artificial Intelligence}

The ascent of computerized agribusiness and its connected advancements has opened an abundance of new information openings. Distant sensors, satellites, and UAVs can accumulate data 24 hours out of every day over a whole field. These can screen plant wellbeing, soil condition, temperature, moistness, and so on. The amount of data these sensors can generate is staggering, and the meaning of the figures is obscured by the torrential flow of data. The idea is to enable ranchers to have a better understanding of the situation on the ground by utilising cutting-edge technology such as far-off detecting, which can reveal more about their situation than the naked eye can perceive. Furthermore, more precisely as well as more rapidly than seeing it strolling or passing through the fields.

Distant sensors empower calculations to decipher a field's current circumstance as measurable information that can be perceived and valuable to ranchers for dynamic. Calculations measure the information, adjusting and learning dependent on the information got. The more data sources and measurable data gathered, the better the calculation will be at foreseeing a scope of results. What's more, the point is that ranchers can utilize this man-made brainpower to accomplish their objective of a superior collect through settling on better choices in the field. Experts believe that 25 to 50 percent of farms are investing in precision farming, which involves using digital technology to improve agricultural processes in order to increase crop yields. Artificial intelligence, automation, and unique monitoring gadgets contained in waterproof enclosures are all aimed to help farmers with task like:

- Plant seeding and spacing

- Growth management
- Water disbursement

- Energy conservation

- Grafting and harvesting

- Plant packaging and preparation

Companies like Climate Corporation have urbanized digital agriculture tools complete with drones, cameras, and sensors to monitor the enlargement and health of crops in both small greenhouses as well as larger indoor amenities the size of small fields. The tracking device generates a range of reports on the environment, plant life, and general growth progress.

\subsection{Soil and Water Sensors}

Maybe the gear having the quickest impact is soil and water sensors. These sensors are strong, inconspicuous and moderately reasonable. Indeed, even family cultivates are thinking that it's reasonable to disperse them all through their territory, and they give various advantages. For example, these sensors can distinguish dampness and nitrogen levels, and the ranch can utilize this data to decide when to water and treat instead of depend on a foreordained timetable. That outcomes in more productive utilization of assets and consequently brought down expenses, however it likewise assists the homestead with being harmless to the ecosystem by preserving water, restricting disintegration and diminishing manure levels in nearby streams and lakes.

\subsection{Weather Tracking}

In spite of the fact that we actually poke fun at our neighbourhood meteorologists, truly mechanized climate displaying is getting progressively refined. There are online climate benefits that emphasis only on horticulture, and ranchers can get to these administrations on committed installed and handheld homestead innovation yet in addition through versatile applications that sudden spike in demand for pretty much any buyer Smartphone. This innovation can give ranchers enough early notification of ice, hail and other climate that they can avoid potential risk to ensure the yields or if nothing else relieve misfortunes to a huge degree.

\subsection{Satellite Imaging}

As far off satellite imaging has gotten more refined, it's took into account constant yield symbolism. This isn't simply bird's-eye-see depictions yet pictures in goals of 5meter-pixels and significantly more prominent. Yield symbolism allows a rancher to look at crops as though the person were remaining there without really remaining there. In any event, looking into pictures consistently can save a homestead a lot of time and cash. Moreover, this 
innovation can be coordinated with yield, soil and water sensors so the ranchers can get notices alongside suitable satellite pictures when threat edges are met.

\subsection{Pervasive Automation}

Inescapable mechanization is a buzz term in the farming innovation industry, and it can allude to any innovation that diminishes administrator responsibility. Models incorporate self-ruling vehicles constrained by mechanical technology or distantly through terminals and hyper exactness, for example, RTK route frameworks that make cultivating and preparation courses as ideal as could really be expected. Most cultivating gear as of now embraces the ISOBUS standard, and that puts on the incline of a cultivating reality where balers, consolidates, work vehicles and other cultivating hardware impart and even work in a fitting and-play way.

\subsection{Minichromosomal Technology}

Maybe perhaps the most energizing approaches in agribusiness innovation is arriving in an extremely minuscule bundle. A minichromosome is a little design inside a cell that incorporates almost no hereditary material except for can, in layman's terms, hold a great deal of data. Utilizing minichromosomes, farming geneticists can add handfuls and maybe even many characteristics to a plant. These attributes can be very perplexing, like dry season resilience and nitrogen use. Notwithstanding, what is generally interesting about minichromosomal innovation is that a plant's unique chromosomes are not modified at all. Those outcomes in quicker administrative endorsement make quicker acknowledgment from shoppers.

\subsection{Rfid Technology}

The dirt and water sensors referenced before have set an establishment for discernibility. The business has just started to understand this foundation, yet it's coming to fruition rapidly. These sensors furnish data that can be related with cultivating yields. It might seem like sci-fi; however we're facing a daily reality such that a sack of potatoes can have a standardized tag that you can filter with your Smartphone to get to data about the dirt that yielded them. A future where ranches can showcase themselves and have faithful shoppers track their yields for buy isn't unrealistic.

\section{Conclusion}

Accomplishing adequacy in food creation alongside the preservation of the climate are the significant destinations of the agribusiness by and by. The requirements in accomplishing this undertaking are: restricting area and water assets alongside the corruption of the ecological wellbeing because of unnecessary utilization of synthetic compounds for nourishment and vermin the executives in horticulture. Anthropogenic exercises for advancement have brought about additional debasement of climate and have prodded the pace of environmental change. Worldwide endeavours have been started for diminishing the impacts of environmental change on earth when all is said in done and farming specifically. These means ought to be praised with the developments underway methods utilized in agribusiness and furthermore logical usage of the native information which is demonstrated as more manageable.

The two unique procedures of horticulture expounded above can be coordinated in the current agribusiness framework without numerous aggravations and can be received on a worldwide scale. Vertical cultivating, which is a new idea in agribusiness, has incredible potential considering the falling area assets for farming due broad urbanization and expansion in per capita pay of the agricultural countries. The procedure however another idea for the agricultural country is of extraordinary guarantee and can effectively address the difficulty regarding amount, quality, and assortment. Natural cultivating then again is a notable idea in horticulture, however requires further investigation and reconciliation of logical information for consolidation in the standard agribusiness to take care of the developing requests. These two unique procedures, with discrete standards are promising roads for worldwide agribusiness and require further investigation in wording exploration and combination in standard for better climate and all around took care of world. In this, taking everything into account changing segment patterns and mechanical headways are conveying new advancements in the field of horticulture. These arising advancements are needed to be utilized reasonably to satisfy the developing needs from current agribusiness. Vertical cultivating and natural cultivating can be embraced as the suitable choices for the traditional farming to satisfy the changing needs and needs of humanity. Further, requirements in appropriation of such practices ought to be tended to and linkages among specialists and ranchers ought to be made for reasonable measures.

\section{References}

[1] Alexandratos N, Bruinsma J "World Agriculture Towards 2030/2050: The 2012 Revision”, ESA working paper No. 12-03. Rome, FAO; 2002.

[2] Biao X, Wang X, Ding Z, et al, "Critical Impact Assessment of Organic Agriculture", J Agric Environ Ethics, 2003;16(3), PP. 297311.

[3] FAO. Evaluating the potential contribution of organic agriculture to sustainability goals. Environment and Natural Resources Service. Sustainable Development Department. FAO's technical contribution to IFOAM's Scientific Conference, Argentina; 1998

[4] Ganeshan M K, Vethirajan C (2021), "The Impact of Technology 
and Agriculture Mobile Applications for Farmers in India", $3^{\text {rd }}$ International Conference on Recent Advances in Management and Technology (ICRAMT-2020) Conference Proceeding (Souvenir), on $8^{\text {th }} \& 9^{\text {th }}$ January 2021 at Invertis University, Bareilly, U.P, India, pp. 372-376.

[5] Garg A, Balodi R, "Recent Trends in Agriculture: vertical farming and organic farming", Adv Plants Agric Res. 2014Volume 1, Issue 4, pp.142-144. DOI:10.15406/apar.2014.01.00023

[6] Gosling P, Hodge A, Goodlass G et al. "Arbuscular mycorrhizal fungi and Organic Farming Agriculture, ecosystems and environment", Volume 113, Issue 1, 2019, pp. 17-35.

[7] Gosling P, Shepherd M, "Long-term changes in soil fertility in organic arable farming systems in England, with particular reference to phosphorus and potassium", Agriculture, Ecosystems and Environment., Volume 105, Issue 1-2, 2005 pp. 425-432.

[8] IFOAM, "Basic Standards for organic production and processing", Germany: IFOAM Tholey-Theley; 1998.

[9] Stockdale EA, Lampkin NH, Hovi $\mathrm{M}$ et al., "Agronomic and environmental implications of organic farming systems", Adv Agron, Volume 70, 2001, pp. 261-327.

[10] Lampkin N, "Organic Farming", Old Pond, Ipswich, England; 2002.

[11] Manida M, Nedumaran G, "The Theoretical Study of Green Marketing in Tamilnadu: Its Importance and Challenges", The International Journal of Analytical and Experimental Modal Analysis, Volume 11, 2019, pp. 3833-3840. ISSN NO: 0886-9367.

[12] Nedumaran G, Manida M, "Green Marketing Impact of the Agriculture Products", International Journal of Advance and Innovative Research, Volume 6, Issue2, 2019, ISSN: 2394-7780.
[13] Nedumaran G, Manida M, "Trends and Impacts of E-Nam in India", 2019, ISBN: 978-81-8094-323-2.

[14] Manida M, Pandiyaraj P K, "A Study on Consumer Behavior towards Usage of Green Products", April 2015, DOI: 10.13140/RG.2.2.28781.13286.

[15] Manida M, Nedumaran G, "Impact of E-Communication on Agriculture Development through CSR in Agri-Farmer in Rajapalayam Taluk", The International Journal of Analytical and Experimental Modal Analysis, Issue XI, pp. 106-114. ISSN NO: 0886-9367.

[16] Nedumaran G, Manida M, "Impact of FDI in Agriculture Sector in India", International Journal of Recent Technology and Engineering, Volume 8, Issue I10, 2019 DOI: 10.35940/ijrte.C1081.1083S19.

[17] Nedumaran G, Manida M, "E-Marketing Strategies for Organic Food Products", International Journal of Advance and Innovative Research, Volume 6, Issue 2, 2019, pp. 57-60, ISSN: 2394-7780.

[18] Nedumaran G, Manida M, "Green Marketing on Customer Behaviour towards Usage of Green Products", International Journal of Advanced Scientific Research and Development, Volume 8, Issue 7, 2018, pp. 67-73.

[19] Knudsen MT, Halberg N, Olesen JE et al., "Global Trends in Agriculture and Food Systems: Challenges and Promises", UK: CAB International; 2005.

[20] Willer H, Lernoud J, T he world of organic agriculture. Statistics and emerging trends in 2014, 15th ed. Switzerland, 2014, pp. 25-32. 